\title{
ENTREVISTA
}

\section{ESTO NO ES UNA ELEGÍA. LA PARTICIPACIÓN POLÍTICA ESTUDIANTIL EN EL DESARROLLO DE LA UNIVERSIDAD DE LOS LAGOS} Entrevista a Pedro Fuenzalida Rodríguez This is not an elegy. the influence of student policies in the development of universidad de los lagos Interview with Pedro Fuenzalida Rodríguez

MARTÍN QUINTANA ELGUETA Universidad de Los Lagos m.quintana@ulagos.cl

En marzo de 2021, la Universidad de Los Lagos perdió a uno de sus académicos históricos. La entrevista que publicamos fue realizada durante el año 2016, como parte de la ejecución de un proyecto de Fortalecimiento de Desarrollo Institucional FDI, financiado por la División de Educación Superior (DIVISUP) del Ministerio de Educación de Chile. Allí conformamos un equipo de trabajo para profundizar la comprensión institucional respecto del rol dirigencial de estudiantes de Educación Superior en la Universidad de Los Lagos. Además de una serie de acciones materiales tendientes a promover y mejorar espacios de trabajo para los equipos dirigenciales, se desarrolló una escuela de liderazgo y se investigó la trayectoria del movimiento dirigencial en la Universidad, desde una perspectiva comparada. Esto es, mirar la relación entre al menos dos generaciones distintas y distantes -en tiempo de dirigencias estudiantiles- para intentar elaborar una cierta guía comprensiva de los nuevos modos de organización estudiantil. Esta forma nos parecía útil para la vida institucional, sobre todo en una 
universidad que sostiene dentro de sus valores centrales la promoción de la participación y el fortalecimiento de la democracia. Como resultado de dicha investigación se publicó, durante el 2018, un artículo en la revista Última Década ${ }^{1}$.

El trabajo mencionado fue posible gracias al testimonio de diversos actores institucionales: dirigentes estudiantiles de diferentes carreras en ese período (2015-2016) y de fases previas al devenir institucional e incluso nacional. Entre otros invitados a narrar su testimonio, estuvo el colega y académico Pedro Fuenzalida Rodríguez.

El año 2021 nos golpea con el prematuro fallecimiento de Pedro; Aunque sostuvimos diferencias políticas, incluso desde nuestra época de jóvenes estudiantes universitarios, fue él quien me invitó por primera vez a desarrollar docencia en el campus Puerto Montt de la Universidad de Los Lagos, allá por el 2005. A pesar de las diferencias, siempre hubo un respeto mutuo que con su partida se transformó en la urgencia de compartir con la comunidad académica esta entrevista in extenso que nos concedió en el marco de ejecución del proyecto $\mathrm{FDI}^{2}$. La entrevista fue diseñada por el equipo que me correspondió liderar y su ejecución la realizó el colega Claudio Vargas, quien gentilmente me ha cedido el derecho de editar y compartir este trabajo.

Como se podrá apreciar, en esta entrevista Pedro recorre aspectos personales, institucionales y de política nacional. Destacan referencias a la memoria espacial institucional, a su historia personal como militante

\footnotetext{
${ }^{1}$ Quintana, M., Saravia, F., Vargas, C., \& Pérez, C. (2018). Continuidades y contrapuntos sociopolíticos entre dos generaciones de dirigentes estudiantiles de la universidad de los lagos. Última Década, 26(48), 72-106. Consultado de: https://ultimadecada.uchile.cl/index.php/UD/article/view/56215/59452

$2 \mathrm{Me}$ correspondió en dicha época la dirección del proyecto de investigación Fortalecimiento de Desarrollo Institucional FDI y la coordinación del equipo de trabajo conformado por los colegas Felipe Saravia y Claudio Vargas.

292 | INTEREDU № 4 VOL. I (JULIO 2021) PÁGS. 291-314. ISSN: 2735-6523
} 
político, como estudiante y actor relevante del devenir de la Universidad. Es un testimonio que valora la trayectoria intelectual y que no trepida en defender posiciones que, aunque polémicas, se reconocen como consistentes. Es muy interesante, además, observar aquí, la vigencia de su análisis respecto de materias como el extractivismo medioambiental y la necesidad de discutir un nuevo marco jurídico nacional, una nueva constitución. Me parece que en sus $\operatorname{dichos}^{3}$ se cristaliza la figura del hombre, del estudiante, del académico, en fin, del ciudadano inquieto y comprometido que fue Pedro. Espero que este acto de hacer pública su palabra, no haya colisionado con su perspectiva sobre la política y la investigación. Mi intención ha sido tan sencilla como honrar su memoria.

\section{$\mathrm{E}^{4}$ : ¿Cuál es su nombre, profesor?}

PF5: Pedro Fuenzalida Rodríguez.

E: ¿Usted que profesión tiene y en qué época estudió en la Universidad? PF: Yo soy Profesor de Biología y Ciencias Naturales y estudié entre los años 1984 y 1989 en la Universidad de Los Lagos.

\section{E: ¿Tuvo militancia política en esos años?}

PF: La tuve, la tengo y probablemente la tendré. Lo que no sé es si cambiará, pero sí, soy militante de la Democracia Cristiana hoy como en el pasado.

\section{E: ¿Militante aquí en Osorno?}

PF: Sí, pero como vivo en la comuna de Frutillar, las militancias están adscritas al lugar donde se tiene registro electoral.

3 Las notas a pie de página corresponden al proceso de edición y no a la transcripción de la entrevista a Pedro Fuenzalida.

4 E. indica entrevistador.

5 PF. Indica Pedro Fuenzalida.

INTEREDU № 4 VOL. I (JULIO 2021) PÁGS. 291-314. ISSN: 2735-6523| 293 


\section{E: ¿Y allá participa también?}

PF: Sí. No tan activamente como antes, pero sí participo.

\section{E: ¿Usted dirigió alguna organización estudiantil?}

PF: Sí, fui Presidente, Secretario, Vicepresidente del centro de estudiantes de la carrera de Pedagogía en Biología. También fui en esa calidad, miembro del Consejo de presidentes y participaba de la Pastoral universitaria. En aquellos tiempos tenía una adscripción religiosa, cuestión que con el tiempo fue derivando en un alejamiento sustantivo de esas manifestaciones doctrinarias, como también de fe; $\mathrm{Y}$ al finalizar mi etapa en la universidad, época de procesos de democratización, fui representante de los estudiantes en el primer Consejo académico universitario con participación estudiantil. Eran parte de ese grupo Claudio Rivera, Alex Soto, Cristian Vittori y Carlos Peña. En ese tiempo también fue presidente de la federación de estudiantes, Oscar Garrido, el actual Rector.

\section{E: ¿En qué años fue eso?}

PF: El proceso de democratización comenzó a finales del 89' y 90', en ese tiempo ya había egresado, aunque aún no me había titulado. El año 1991 fue mi último año de expresión político gremial como estudiante en la Universidad. Después en el 2002, fui Presidente de la Asociación de profesionales de la Universidad. En ese tiempo era funcionario administrativo y ocupé el cargo de presidente elegido por mis compañeros de la asociación.

\section{E: ¿Usted fue dirigente desde que ingresó a la Universidad?}

PF: No, porque en primer año los mechones no teníamos esas posibilidades de ser dirigentes, salvo ser delegado. Yo fui miembro de la directiva de la carrera a finales del segundo año. Lo recuerdo muy bien 294 | INTEREDU № 4 VOL. I (JULIO 2021) PÁGs. 291-314. ISSN: 2735-6523 
porque estábamos debatiendo en el segundo semestre, sobre los procesos políticos que estábamos viviendo en plena dictadura. El año 1984, en el segundo semestre, recuerdo haber tenido una primera acción verbal pública y al parecer hubo mucho respaldo al planteamiento que yo sostenía, porque después forme parte de una directiva.

\section{E: Usted me dijo que había estado en tres frentes: en la carrera, en un colectivo pastoral y en la consejería superior.}

PF: Claro, pero la consejería era representación estudiantil, dentro de la estructura de gobierno en la universidad yo era consejero académico. En ese entonces, teníamos la misma estructura de poder colegiado en el Instituto Profesional de Osorno (IPO) que en la Universidad que hoy día tenemos. La estructura colegiada básica era el consejo académico donde nosotros participábamos. En la junta directiva no había representantes estudiantiles, salvo el presidente de la federación que participaba con opinión en algunas cuestiones.

\section{E: O sea, ¿en ese tiempo la figura de consejero superior no existía?}

PF: La figura del consejero fue producto de las negociaciones y del proceso de construcción política democrática que hicimos nosotros para institucionalizar la participación de los estudiantes. Cuando estudiaba en pregrado, no había participación estudiantil por las características propias de la dictadura, la participación estudiantil o estamental estaba prohibida, solo se hacía a través de los académicos; pero los académicos no tenían elecciones, eran designaciones y el rector delegado era el coronel de ejército Mario Marshall L'huillier. En ese tiempo, al finalizar el $89^{\prime}$, después del plebiscito del 88', ocurrió un segundo plebiscito sobre reformas constitucionales que atenuó los sesgos ideológicos. Atenuar no significa que los haya suprimido, porque la constitución todavía mantiene sesgos ideológicos antidemocráticos. 
Por nuestra parte, iniciamos como dirigentes estudiantiles un proceso de democratización en el que conformamos, junto con otras agrupaciones gremiales de la universidad (de los funcionarios que hoy día se denominan AFUDEL y la asociación de académicos), un espacio que se llamó triestamental. En ese momento, después del plebiscito de 1989, Mario Marshall L'huillier renuncia al cargo y asume un primer rector delegado civil que fue (si no me equivoco) el profesor Dieter Konow y después de él, Juan Carlos Uribe, aunque tal vez me equivoque en la alternancia. En esos procesos nosotros participábamos activamente. Íbamos a las asambleas de los académicos y teníamos asambleas permanentes en una sala de estudios ubicada en la plaza debajo de la federación, esa plaza que hoy denominan con un nombre no muy apropiado (plaza de los flojos). Ahí había una sala de estudio y había un gran fogón, donde nos reuníamos todos los estudiantes de esa época. Era nuestro centro de reuniones, de asambleas, de debate, de estudio, de vida cotidiana y de construcción de amistad. Al lado estaba el casino que era un poco más pequeño que el actual. La oficina de la federación de estudiantes era lo que estaba en el entretecho, porque no existía ese segundo piso que existe hoy. La oficina era el entretecho, en la misma ubicación que tiene ahora, pero no con las dimensiones actuales ni su habitabilidad. Era como una palomera. Tenía dos espacios, una oficina donde se atendía público y una oficina de reuniones, donde hacíamos las asambleas con los dirigentes de las carreras, dirigentes políticos e incluso se hizo una especie de huelga de hambre, que era más bien un ayuno.

\section{E: ¿Los objetivos de ustedes para participar como dirigentes estudiantiles en aquella época eran políticos, institucionales?}

PF: El que llegaba a la federación de estudiante, ocupaba el cargo de dirigente gremial, fundamentalmente, con objetivos políticos y los que 296 | INTEREDU № 4 VOL. I (JULIO 2021) PÁGs. 291-314. ISSN: 2735-6523 
teníamos actividad política éramos personas que teníamos suscripciones ideológicas doctrinales expresadas partidariamente -en la mayoría de los casos-. Había compañeros que se definían como independientes, normalmente eran independientes de izquierda, pero esas eran independencias medias "truchas", medio opacas; tú sabías que su independencia era más bien funcional, su motivo era acceder al cargo; en realidad eran militantes o adherentes en la clandestinidad de alguna corriente política. Como no existía registro electoral, no había forma de probar si eran o no eran independientes. Lo segundo: el propósito fundamental de la organización, en ese tiempo, era deponer la dictadura. Era una especie de objetivo inalcanzable para un grupo de estudiantes, pero que en términos de expresiones colectivas, de movilizaciones nacionales, de las tensiones que se producían en las confrontaciones al interior y fuera del partido, era un objetivo nacional que obedecía a esta ola democratizadora y lo fundamental era la recuperación o la restauración democrática. No era posible eso, si no había deposición de la dictadura. Esas demandas se hacían desde distintos lugares. Con el concepto "lugares" no me refiero solo a lo físico, que ya era importante, pues como sabrás, en ese tiempo, en esta institución había gente que no solo era de la región, Veníamos de diversos lugares. Pero cuando digo lugar, aquí, me refiero a lugares ideológicos. A posiciones, en las que había algo en común: la deposición de la dictadura.

En ese tiempo también había otras demandas institucionales. Nos parecía injusta la clasificación de Instituto Profesional, pues esta institución, en su sede Osorno, había sido sede de la Universidad de Chile y en Puerto Montt, sede de la Universidad Técnica del Estado; Por tanto, otra de las demandas más importantes para nosotros era la recuperación del estatus universitario de nuestra institución. Había otras demandas que tenían que ver con el Crédito Universitario, con los sistemas de beneficios y de 
apoyo a los estudiantes. Nuestra universidad, si hoy en día es pobre, antes lo era mucho más y nuestra biblioteca también muy limitada: esa pobreza nos movilizaba. Era una institución pequeña en número de estudiantes, alrededor de dos mil en este espacio, que es bastante menos de lo que tú ves hoy día. Nuestra presencia en infraestructura se reducía al cuerpo central, los pasillos generales que arman el pabellón A, B, y C; los laboratorios que antes eran las salas de clases conformaban el pabellón $\mathrm{C}$ y el D, cerca del sector de acuicultura; el pabellón E, que sigue siendo el bloque con más pisos de salas -sin considerar las nuevas infraestructuras llamadas aulas virtuales-; y el F donde funcionaban las unidades administrativas, las asistentes sociales, asuntos estudiantiles, secretaría de estudios y control curricular.

\section{E: Usted hablaba que había dirigentes que declaraban su independencia política, pero en el caso de las personas que sí tenían militancia y eran dirigentes ¿había influencia de los partidos sobre ellos?}

PF: Yo dije algo parecido antes, pero no es a eso a lo que me quería referir. Cuando decía que había dirigentes estudiantiles que sostenían su independencia, lo que yo te señalo es que esa independencia era opaca, porque siempre había alguna relación con los partidos políticos. Nosotros también podríamos haber llevado independientes DC, pero eran siempre personas que estaban vinculadas orgánica, teórica, doctrinal, ideológica y políticamente a la línea del partido. Entonces, eran independencias opacas, a eso me refiero. Siempre hubo vinculación partidaria, al menos en los casos más conocidos que se declaraban como independientes. No hubo ninguno que no tuviera relación partidaria; puede ser que alguna carrera haya tenido entre sus dirigentes algunos independientes con absoluta prescindencia de los partidos: eso lo desconozco y si es que los hubo, no lo sabemos. Pero en la mayoría de los dirigentes públicos 298 | INTEREDU № 4 VOL. I (JULIO 2021) PÁGs. 291-314. ISSN: 2735-6523 
estudiantiles había relación con las estructuras partidarias y las redes partidarias de ese momento. También sucedía en las organizaciones sociales como las federaciones campesinas, las organizaciones indígenas, los sindicatos, que estaban fuertemente influidas por los partidos políticos.

\section{E: ¿Ustedes se vinculaban con otras organizaciones internas o externas} a la universidad?

PF: La federación de estudiantes siempre estuvo articulada. Al ser sus dirigentes representantes de partidos políticos, tenían relaciones con otros dirigentes políticos y sociales, que eran actores políticos de sus propios partidos. Por ejemplo, en mi calidad de presidente de la carrera de pedagogía en biología siempre estuve en articulación con otros presidentes de carreras que también eran demócrata cristianos, que formábamos parte de lo que era el núcleo demócrata cristiano universitario. También nos vinculamos con dirigentes sociales de la federación campesina, organizaciones indígenas, sindicatos de la construcción $\mathrm{u}$ otros referentes sociales; Asimismo, nos acercamos a funcionarios públicos que eran militantes demócrata cristianos o vinculados a la alianza de referentes del bloque como la alianza democrática o lo que era el MDP (Movimiento Democrático Popular) para la gente de izquierda (de esa izquierda de entonces). Entonces, siempre hubo una relación con las organizaciones. En mi caso particular, mis redes de relación social estaban armadas no solo con las estructuras y los dirigentes de los partidos políticos, también mi colaboración se vinculaba a la acción con el movimiento mapuche, expresado en la organización mapuche Newenmapu y con la federación campesina con la que colaboraba en menor medida, pero que estaban socialmente articulados. Entonces, no era posible ser dirigente en la universidad y no tener una red con otras organizaciones con las que participábamos en las acciones de protesta, en las movilizaciones, en las marchas, en las asambleas, en las 
peñas ${ }^{6}$ como expresión de protesta. Estas eran un espacio donde se canalizaba, se construía la formación política, se hacía presencia: tanto en la federación de estudiantes como en las organizaciones sociales y también en las organizaciones pastorales.

\section{E: Cómo convocaban al estudiantado: ¿hacían llamados, usaban afiches, hacían murales?}

PF: Lo que no usábamos en ese tiempo eran las redes sociales que hoy día conocemos, porque no existían. En aquel entonces usábamos mucho la radio. Había radios que tenían adscripciones políticas cercanas a nosotros, de vinculación y compromiso ético como La Voz de la Costa, que era muy importante. Había otras radios que daban las noticias haciendo énfasis en "escándalos violentistas" como la Radio SAGO u otras radios de derecha o de supuesta prescindencia política, pero que obedecían a las normas establecidas en el marco de la legislación que imponía la dictadura. También se usaba el panfleto, el afiche, los lienzos gigantes que eran de nylon. Nada de lo que hoy día existe en términos de redes era posible. Seguramente había otros mecanismos que cada partido tenía, sobre todo aquellos que tenían redes y estructuras que se movilizaban en la lógica de la clandestinidad, pero esas las desconozco, pues yo no participé de un partido de esas características.

\section{E: El espacio de convocatoria era al lado del casino ¿pero también se reunían fuera de la universidad?}

6 Las peñas se popularizan en Chile, durante los años $60^{\prime}$ y $70^{\prime}$ a propósito de la famosa Peña de los Parra. Se trata de una reunión festiva con canto en vivo de música preferentemente folclórica y comidas y bebidas tradicionales. Durante la dictadura, adquieren una relevancia fundamental como espacio de reunión y expresión cultural del mundo opositor al pinochetismo.

300 | INTEREDU № 4 VOL. I (JULIO 2021) PÁGS. 291-314. ISSN: 2735-6523 
PF: Sí, siempre. Era habitual que las decisiones políticas que se canalizaban por medio de las organizaciones ocurrieran fuera de la universidad. El diseño de las estrategias de movilización nacional y que debían tener expresiones locales, no se planificaban en un centro de alumnos. Más bien se suscribían acuerdos nacionales que disponían las estructuras y las élites de los partidos políticos. Existían distintos espacios que uno tenía para reunirse; inclusive en reuniones con amigos, uno podía tomar decisiones políticas que pudieran afectar a la organización, eso ocurría antes y probablemente siga ocurriendo. Desconozco como operan hoy día los estudiantes, salvo lo que veo en las movilizaciones, pero la dinámica interna no sé cómo funciona.

\section{E: En relación a los modos de articulación, ¿eran los mismos dirigentes que se articulaban con otras organizaciones y ahí se iba creando la red o había otras metodologías?}

PF: No existe una única forma de articulación. La más visible siempre son los dirigentes, pero la forma de articulación más efectiva que teníamos en ese entonces era en el marco de las relaciones partidarias, es decir, los acuerdos políticos que se establecían a nivel nacional tenían una reproducción local. Por ejemplo, nosotros teníamos alianza con el PS (Partido Socialista) y necesariamente tenía que haber una lista donde hubiera una articulación entre PS y la DC. Ahora, yo creo que en el caso de Osorno, al ser una universidad pequeña, teníamos ciertas libertades que no se podían dar en la Universidad de Chile, por ejemplo, o en la Católica. Nosotros podíamos prescindir del PS o el PS prescindir de nosotros y llegar a un acuerdo con el Partido Comunista. Entonces había ciertas relaciones de articulación política que, en el caso nuestro, por ser más pequeña, de menor impacto, nos daba ciertas libertades que nos permitía flexibilizar los acuerdos nacionales. Nosotros podíamos, en 
muchas ocasiones, presentar listas junto con el PC y también, en otras ocasiones, presentarnos junto con el PS y/o los tres partidos juntos.

\section{E: ¿Y por qué aquí sí y en la Universidad de Chile o la Universidad Católica no?}

PF: Bueno, yo creo que eso tiene que ver con varias razones; primero, que al ser una universidad pequeña los liderazgos no se reproducen ni son tan masivos como para decir "vamos a tener un liderazgo que va a tener tal impacto", eso en el espacio local. Segundo, que al ser pequeña nuestra universidad -por muchas innovaciones que nosotros hiciéramos- no alterábamos el devenir nacional. Por ejemplo, la triestamentalidad para democratizar las universidades fue una innovación que nosotros hicimos y con ello fuimos la primera universidad del país en iniciar un proceso democratizador. Fuimos la primera universidad que tuvo participación estudiantil en las estructuras colegiadas, la primera universidad que participa con los estudiantes en una ponderación de igual a igual en la elección de jefes de carrera: eso no se hace en otras universidades. Esto quiere decir que por ser pequeña, teníamos ciertas libertades que nos permitían estos ejercicios de profundización democrática. Además, más allá de nuestras posiciones políticas, había espacios de acuerdo con aquellos que pudiéramos haber pensado distinto, por ejemplo, con el PC. Yo creo que en el caso de la Universidad de Chile o la Universidad Católica, como generaban un impacto político nacional, entonces se les hacía más difícil innovar. Todavía existe un anticomunismo horroroso en Chile y tú lo ves dentro de la Democracia Cristiana. ¿Tú has escuchado lo que dice Walker, Zaldívar o Gutenberg Martínez? Dicen que el margen de posibilidades de llegar a un acuerdo político con el PC es escaso, salvo que esté en el marco de un acuerdo programático como es el caso de la Nueva Mayoría, que siempre tiene un plazo finito. Yo aquí creo que soy 302 | INTEREDU № 4 VOL. I (JuLIO 2021) PÁGs. 291-314. ISSN: 2735-6523 
más cercano a la concepción que tenía Aldo Moro, que quería construir un acuerdo de justicia compartida. Nosotros, en el Instituto Profesional de Osorno, lo podíamos hacer porque lo que hiciéramos en Osorno no se iba a notar significativamente en el discurso, ni en la acción política nacional. Un grano de arena blanca no hace que la arena en Maicolpue sea blanca o un grano de arena gris en una playa no hace que la playa sea gris: son experiencias y teníamos cierta autonomía. Además, éramos tan pequeños como grupo que no había tiempo para generar rencores significativos. Podíamos tener diferencias y podíamos pelearnos un día, pero salíamos de estos procesos y seguíamos amigos. De hecho, hoy día, nos encontramos con muchos que teníamos posiciones radicales diferentes, encontradas y confrontadas en esos tiempos de efervescencia ideológica. Podemos compartir un café, un trago, rearticular o construir, rehacer las amistades que están en el margen de las relaciones políticas. Es lo que yo podría llamar amistades cívicas. No bajo el concepto republicano que se plantea mucho en Chile, sino con amistades cívicas que pueden ser amistades muy profundas y donde las diferencias se respetan.

\section{E: ¿Cómo era la relación con los directivos de la universidad?}

PF: Bueno, hay otras personas que te pueden dar una apreciación más directa sobre eso porque estuvieron en la primera línea de conversación, presidentes de la federación que les tocó negociar directamente con las autoridades de la dictadura en ese tiempo. Pero mi impresión es que dentro de todo grupo de poder hay personas que entienden la relación con los otros de manera distinta. Hay algunos que tenían una posición radicalmente represiva y hay otros que tenían unos niveles de apertura. Puedo señalar que hubo una movilización muy grande y el que era jefe de mi carrera en ese tiempo, don César Triviño, nos protegió a todos los que éramos dirigentes de la carrera para que no fuéramos objetos de un sumario. Él que era Jefe de Carrera, en esos espacios de poder, hizo INTEREDU № 4 VOL. I (JULIO 2021) PÁGs. 291-314. ISSN: 2735-6523| 303 
esfuerzos para aceptar que había personas que pensaban distinto a él, que pensaban distinto al régimen político y que no ameritaban una sanción de esas características por aquello. En cambio, había otras personas que no tenían ningún empacho en decirte: "si usted no tiene plata, ¿para qué estudia?", por lo tanto, la relación se hacía más compleja. Cuando alguien te dice que tú no tienes derecho a estudiar porque no tienes plata, es un acto de violencia muy significativo y hace que tu relación con esa persona sea distinta. Aun así, siento que había cierto margen de tolerancia de parte de las autoridades delegadas aquí, en esta universidad, en el Instituto Profesional Osorno, pensado en lo que ocurría en otras universidades donde los sumarios y las expulsiones eran habituales. Incluso con la llegada de la democracia, ocurrieron expulsiones y sumarios como los de la Universidad Católica de Temuco, por ejemplo, y otras universidades, por acciones de carácter político. O lo que ocurre a veces en la Universidad Alberto Hurtado hoy, donde hay dirigentes que son expulsados o son sujetos de acoso constante a través de sumarios, investigaciones y la vigilancia de guardias detrás de ellos. Yo creo que a veces hay acciones, en algunas universidades, que se entienden con convicciones valóricas democráticas distintas a las de la dictadura. Tienen acciones tanto o más represivas que las que nosotros vivimos acá. Yo creo que hubo un cierto margen de tolerancia y eso se agradece también.

\section{E: El Rector, los Jefes de Carrera, Jefes de Departamentos, ¿también eran designados por la dictadura?}

PF: En ese tiempo todo cargo era designado por la dictadura de forma directa o indirecta. Se reconoce que en ciertos casos hubo actos de tolerancia y aceptación de una crítica que era justa, pero eso no significa que las universidades no hayan estado infiltradas. No, a mí no me cabe la menor duda, sin conocer un caso puntual, que tanto en el cuerpo de 304 | INTEREDU № 4 VOL. I (JuLIO 2021) PÁGs. 291-314. ISSN: 2735-6523 
profesores como entre los estudiantes y estructuras directivas, había gente que funcionaba como informante. En ese tiempo se le catalogaba como "sapos", gente que se encargaba de hacer la recolección de información para la inteligencia política y de represión policial. Entonces no había ninguno de nosotros que, en algún momento, no haya sido objeto de alguna atención por parte de ellos, sobre todo cuando lo hacíamos públicamente. Si tú te paras en una asamblea y dices que hay que avanzar en los procesos de democratización, en plena dictadura, entonces corres el riesgo de ser informado como activista peligroso... en fin. Cualquiera, no solo los que fuimos dirigentes activos en ese entonces, incluso personas que no fueron actores públicos como lo fuimos nosotros, corrían ese riesgo.

\section{E: En otro plano ¿qué lo motivó a ser dirigente?}

PF: La verdad es que uno nunca sabe lo que lo motiva a ser dirigente, porque tú puedes observar hoy día que yo no tengo la política como mi oficio. La política para mí, en términos de acción pública, es un grado, es una combinación (así lo voy a llamar). No sé si es el concepto más apropiado, pero es una relación dialéctica entre el deber y el derecho. No puedo ejercer un derecho si no ejerzo mi deber, así lo planteo y detrás de esa hay, a mi gusto, una convicción de que uno tiene que implicarse siempre en los procesos sociales y en luchas políticas que se orienten a la construcción de procesos de justicia. Eso no significa que uno tenga que adscribirse siempre a un grupo determinado, más si las lógicas de ese grupo pueden vulnerar los derechos y la justicia. No puedo apoyar aquello, al menos desde mi percepción ideológica. Yo creo que muchos de nosotros tenemos historias de vida que fueron un poco convulsionadas: pobreza, marginalidad, maltrato. Entonces tienes distintas opciones, pero las posiciones polares de esas opciones están en que o bien te sometes y asumes una posición de sumisión y sin posibilidad alguna de expresar libremente lo que piensas o, por otro lado, optas por INTEREDU № 4 VOL. I (JuLIO 2021) PÁGs. 291-314. ISSN: 2735-6523| 305 
una posición de rebeldía explícita. Yo creo que en uno hay algo de eso, una expresión de rebeldía que lo lleva a ampliar los procesos de provisión, de riesgo vital y todas esas cosas. Hay algo de rebeldía en no aceptar las condiciones de vida que nos tocó vivir, no como derecho natural, sino entender lo que es un proceso social, una construcción humana en que esas condiciones de vida son producto de relaciones de poder que no son justas.

\section{E: ¿Cuándo entró a la Universidad, ya era militante de la democracia cristiana?}

PF: Sí.

\section{E: ¿Y cómo llega a ser militante de la Democracia Cristiana?}

PF: Tenemos que situarnos un par de años antes del año 84. Yo soy de un lugar que se llama Hualañé y mis mayores experiencias de vida en términos de complejidad, de frustración, de pobreza, de marginalidad, de maltrato, de hambre y de privaciones se dan en ese periodo. Entonces en esa época, había también esta forma, este estilo de rebeldía, a veces confrontacional. Uno con el tiempo va madurando esos procesos, diciendo: ¿hasta qué modo uno puede regular la confrontación o puede lograr éxito sin confrontación? En ese tiempo se generó una movilización porque estaban desvinculando del trabajo a un profesor de inglés. Yo estudiaba en una escuela rural y justamente cuando salí de octavo básico, se crea el liceo. Si no se hubiese creado, no hubiese podido estudiar, porque tendría que haberme ido a vivir a Curicó o a Talca. En fin, cuando se crea ese liceo nosotros no teníamos muchos profesores, incluso las clases las hacían a veces los mismos profesores de básica. Una vez llegó un profesor de inglés muy bueno y lo despidieron. Fue ahí que nos movilizamos. Antes fuimos a hablar con el alcalde, que era un alcalde delegado por la dictadura. Con esa experiencia comenzó mi rebeldía, eso 
de no aceptar las cosas que nos habían pasado. Esa movilización y esa experiencia me lleva a conocer a algunos profesores que me invitan a una reunión a Curicó. Fui, estuvimos conversando y ahí me vinculé a algunos que eran de la Democracia Cristiana. No había mucha oferta en términos de doctrinas partidarias. Quizá si hubiese conocido a otras personas me habría vinculado a otro movimiento, pero con las personas que me invitaron me vinculé. Había un profesor de química que era del Partido Comunista y otro profesor de castellano que era de la Democracia Cristiana, y así empezamos a conversar. Fui a algunas actividades, después fui a algunas jornadas de formación política y fui conociendo otra mirada de la vida, a conocer otras construcciones culturales también. Hualañe era un sector muy rural en ese tiempo. Imagina, por ejemplo, que solo escuchábamos la radio local. Escuchábamos la música habitual que a mi me gusta mucho: corridos y la música folclórica, algo de cumbia. Entonces cuando llegas a un lugar urbano, donde hay otras expresiones culturales, empiezas a escuchar otra música como el canto nuevo. Ahí escuché por primera vez la Cantata Santa María. La escuché en un encuentro de jóvenes en el marco de una acción pastoral de ese tiempo; pero la acción pastoral, era la pantalla para la formación política de distintos partidos. Escuché la cantata y entonces empecé a descubrir otras cosas. Ya en ese tiempo tenía claro que la universidad era mi camino, no había otro: era eso o la realidad que vivía. Creo que el espectro tampoco era muy grande: así llegué a la política. Acá me relacioné con algunas personas, tenía resuelta mi militancia y me vinculé también con la gente de la pastoral y con las organizaciones sociales. Desde la política llegué al mundo mapuche en el que hago todo mi trabajo sobre educación intercultural, que hoy día es mi campo laboral. 


\section{E: ¿Qué le aportó a su desarrollo personal, a su vida, el hecho de haber sido dirigente?}

PF: Muchísimo. Te lo expreso de esta forma: no hablaba en público, no sabía como articular una frase, era muy, muy tímido. Hoy día eso no se nota mucho, aunque de esa timidez todavía quedan vestigios. Al ser dirigente pude atreverme a hablar, me encontré en la obligación de hacerlo, en la necesidad de comunicar algunas ideas que a veces uno no logra explicarlas bien. Todavía tengo certeza de esos riesgos o limitaciones, pero esas mismas limitaciones son para mí una fortaleza en otro campo: en el desarrollo de mi lenguaje. Te cuento una experiencia. Yo estaba en Punta de Tralca, había varios dirigentes de la Democracia Cristiana de ese entonces: Claudio Orrego, Sergio Micco, Felipe Sandoval, Yerko Ljubetic, Tomás Jocelyn-Holt, que son los que ocuparon una primera línea en la política de ese entonces. Yo los escuchaba y no entendía nada de lo que estaban hablando. Mis limitaciones eran enormes, venía de un lugar rural, mis orígenes de pobreza eran muy duras, mi madre no sabía ni escribir, no entendía y en ese entonces me dije "esto no me puede ocurrir nunca más" y desde ahí empecé a enriquecer mi capacidad lingüística, de producción. No la he mejorado totalmente, tengo muchas cosas que trabajar aún, pero he avanzado. Entonces, ser dirigente me ha aportado mucho, me ha permitido ver la realidad desde otra perspectiva, también he aprendido que esa rebeldía de entonces, la puedo expresar vehementemente en la construcción de un discurso político. He aprendido también que quejarme sirve, pero no es suficiente. Necesito que mi queja, más la queja de otros y la de otras, se articulen y construyan un discurso político común. Si no hubiese sido dirigente no sé qué mundo posible hubiese vivido, no lo sé. 
E: ¿Usted ha estado, desde que egresó del pregrado, en esta institución? PF: No. A ver, tengo treinta y dos años en el sur. Piensa que mi referencia de sur es de alguien que nació y creció en la séptima región. Llegué a la Universidad (Instituto Profesional de Osorno) en 1984 y estuve hasta 1991, cuando fui dirigente. Egresé, en todo caso, en 1989 y después me puse a trabajar, pues me casé el año 90. Primero lo hice en la Municipalidad de Osorno, durante un año, después en la Corporación de Desarrollo Social de Osorno, hasta 1997. Luego de eso y, desde entonces, trabajo en la Universidad de Los Lagos. Primero en Puerto Montt, donde me invitó Alejandro Santibáñez. Trabajé en ese entonces en un proyecto de educación a distancia, cuando en la universidad estaba el boom de los Programas Especiales para Trabajadores $(\mathrm{PET})^{7}$, que nos trajo beneficios, pero también una larga consecuencia en el deterioro de la imagen institucional. En todo caso, no lo sanciono en términos tan negativos pues, sin su existencia, es probable que nuestra pobreza hubiese sido mayor. No tendríamos nada. Pero volviendo a la pregunta, entre 1991 y 1997, no estuve vinculado a esta institución. De los treinta y dos años que llevo en el sur, veintiséis años he estado en la Universidad, como estudiante, dirigente, como funcionario administrativo y después como académico, a partir del 2005.

E: ¿Cómo observa usted las transformaciones que han ido sucediendo en la Universidad respecto de la participación estudiantil? Se lo pregunto porque en su época de dirigente había mucha influencia partidaria, cuestión que hoy no es tan visible.

\footnotetext{
7 Se trataba de cursos académicos en horarios especiales y con currículo acotado que favorecía la titulación de trabajadores, generando un nicho de negocio para la Universidad pero que, sin embargo, en muchos casos implicó una diferencia en calidad para estudiantes de una misma carrera que se dictaba en lugares distintos del país.
}

INTEREDU № 4 VOL. I (JULIO 2021) PÁGs. 291-314. ISSN: 2735-6523| 309 
PF: Es que había una fuerte efervescencia política dado el contexto histórico que vivíamos. Hoy día no. Lo que no se nota es una influencia partidaria institucionalizada como la de la Democracia Cristiana (DC), del Partido Socialista (PS), del Partido por la Democracia (PPD), tal como fue casi hasta el año 2000. Hay referentes políticos partidarios todavía presentes, yo los he observado. He percibido también la propaganda que aparece ahí, la presencia de partidos como el PC, la DC y del PPD. Aunque no se note una presencia muy fuerte, siento que la hay. De la derecha también hay presencia, pero no se ven orgánicamente articulados como lo éramos nosotros en tiempos de dictadura. Había mucha participación estudiantil. Cuando había elecciones de federación de estudiantes, nosotros llegábamos antes del amanecer y nos tomábamos los techos y empezábamos a colgar carteles. El grupo comando que llegaba primero, ocupaba los mejores lugares para su propaganda y los pasillos se oscurecían, porque no había espacio donde no hubiera afiches, consignas, cualquier cosa que significara relevar la oferta política para la Federación. Eso era muy interesante, muy intenso. Logramos niveles de participación institucional de los estudiantes en esa estructura cerrada que eran las universidades: participación, decisión política y gobernanza universitaria.

He percibido que junto con este proceso político, social e histórico llamado globalización o mundialización y todos los reacomodos del modelo neoliberal, como una expresión más radical del capitalismo, nos han ido llevando a ser sujetos más individualistas y tú lo observas en los estudiantes y lo observas en nosotros mismos. Yo tengo casi la convicción de que se nos puede caer el cielo y nosotros no nos vamos a inmutar colectivamente y muchos de mis colegas que en ese tiempo eran dirigentes activos, se van a inmutar mucho menos que yo. Ese individualismo ha cambiado a las personas. Ha pasado a ser más importante para ellos mejorar sus condiciones de vida familiar o 310 | INTEREDU № 4 VOL. I (JuLIO 2021) PÁGs. 291-314. ISSN: 2735-6523 
individual, por sobre el concepto de un bien común, no mirado en términos bíblicos, sino más bien en términos de justicia social. Yo creo que a algunos de ellos les ha afectado más que a otros. No digo que a uno no le afecte. Vivimos dependientes de las tarjetas de multitiendas y todas esas cosas, aunque algunas veces participamos de una marcha, pues nos parece que hay que hacerlo.

Hay una realidad que a mí me incomoda bastante más. Esos espacios de participación estudiantil en los cuerpos colegiados y en la toma de decisiones institucional, esos que conquistamos en los años 90, son espacios relevantes. Espacios pequeños como la participación en un consejo de carrera, creo que son relevantes pues permiten discutir cuestiones curriculares y valóricas; participar en la construcción de ese currículo me parece fundamental. Pero sucede que esa participación se ha ido desechando. Cuando los estudiantes hoy día dicen que no hay participación en la universidad, yo digo que es una verdad a medias, porque a mí me gustaría que la participación fuera mucho más activa. El problema que tiene la institucionalización de la participación es que cuando elegimos a alguien, esperamos que él participe y el resto se retira. Hemos perdido un mayor protagonismo en los espacios de participación, perdida sistemática, y ese es el gran triunfo del capitalismo radical, del neoliberalismo. Que la participación se institucionalice en cuerpos corporativos a través de representantes, nos hace abandonar el sentido del bien común, nuestra responsabilidad colectiva con los procesos sociales y políticos.

Hay un hecho que para mí es importantísimo, y siento una gran ausencia de los estudiantes en ese tema. Mi impresión es que a partir del 2006 y 2011, que son los hitos que nos permitieron pensar más allá de los límites con el concepto de gratuidad y fin al lucro en la educación superior, nos enseñaron a nosotros, los que movimos límites en el pasado, 
que nos quedamos dormidos. Siento, sin embargo, que un gran grupo de dirigentes y de estudiantes están trabajando en torno a una consigna y sin construcción de debate sobre derecho social, sobre el marco jurídico. Eso es lo que tenemos que discutir ahora y no veo que haya interés en hacerlo. Yo soy partidario de la asamblea constituyente, pero hoy día tenemos este espacio de discusión institucional como los consejos locales, los cabildos o los encuentros locales de grupos y yo no veo a la Federación de Estudiantes en eso. No veo a estos grupos movilizados políticamente. Lo que importa es que si pensamos en la educación como un derecho social, tenemos que pensar en otros temas también: ¿cómo transformamos la realidad, cómo discutimos temas de interés común como el medio ambiente para esta región? La cuestión de la marea roja y el impacto dañino de las salmoneras es tan relevante como el daño ambiental de las forestales. Entonces ¿cómo lo hacemos? ¿Qué sentido tiene ir a una barricada, prender neumáticos? Para algunos sí que es necesario hacerlo, pero tenemos además que construir contenido, tenemos que cambiar el marco jurídico para que eso -el deterioro ambiental o el lucro en la educación- no vuelva a ocurrir.

Yo valoro de manera muy significativa la emergencia de organizaciones partidarias, a partir de dirigentes estudiantiles del 2011, como Revolución Democrática o la Izquierda Autónoma no hablo de Karol Cariola ni de Camila Vallejo porque ellas tienen una estructura ya mas antigua, que son más disciplinadas que los otros partidos. Entonces ellos van a constituir una alternativa y seguramente van a desplazar a los partidos como el mío o como otros, pero ¿dónde están en estas discusiones? Esta discusión hay que hacerla, eso me parece. Hay que hacer la lucha que se está haciendo, sin lugar a dudas, pero la otra, que es la ideológica, la doctrinaria, la de contenido, no la podemos dejar de 
nuevo en manos de un grupo de elite, que se considere iluminado, sino vamos a caer en un régimen parecido.

\section{E: Para terminar ¿cómo ve usted la participación hacía el futuro?}

PF: Creo que tengo que establecer la participación en tres niveles. Una, mi concepción utópica de participación que queda explícita un poco en lo que yo te expresaba: debiera haber una participación política y social más activa. Cuando digo política-social estoy incluyendo el campo de la cultura; debiera ser una participación cultural, pero no quiero decirlo así porque a veces suele pensarse que lo cultural suprime lo político, aunque el arte sea una expresión política, pero prefiero enfatizar en lo políticosocial. Para eso necesitamos modificar algunas acciones de resistencia contra el avance de expresiones culturales y lingüísticas coloniales. El inglés, castellano, francés son lenguas que hoy día nos permiten comunicar, pero necesitamos la emergencia de las lenguas ancestrales, necesitamos avanzar en el proceso de reconocimiento de esas lenguas, aceptarlas dentro de la universidad como expresión de conocimiento tan legítimo como el conocimiento científico emanado desde la modernidad. A mí me parece que necesitamos procesos político-epistémicos que generen estructura, continuidad y articulaciones y eso no se está dando en el campo de lo académico. Otra es la participación política más inmediata. La veo empobrecida aquí en la Universidad de Los Lagos: lo veo en los académicos, en los estudiantes y en los funcionarios; los veo fragmentados, discutiendo cuestiones accesorias y no lo sustantivo. Si se pensara en lo sustantivo, probablemente la fragmentación se terminaría y no importaría tanto quien tiene mayor espacio, más propaganda pegada en la pared. Lo que importa más es qué hay de común en todas esas propagandas, que nos permitan a nosotros avanzar. En el espacio local, la participación la veo muy debilitada y estoy alarmado de la expresión político-social para la discusión constituyente: alarma no porque me INTEREDU № 4 VOL. I (JULIO 2021) PÁGs. 291-314. ISSN: 2735-6523| 313 
preocupe que haya demasiada discusión, sino justamente porque no la hay. Mi estado de alarma es distinto al de la derecha. La derecha tiene una alarma que teme, le preocupa que las masas opinen y construyan un país distinto. Mi preocupación es que creo que la discusión no se está realizando y ahí tenemos que avanzar. Se ha institucionalizado y pensamos que todo esto debe funcionar como en juntas de accionistas o juntas directivas y eso no funciona en mi opinión. Menos en una institución pública, donde el espacio de lo público es consustancial a la función que nosotros desarrollamos en ella, ya sea para el estudiante, para el funcionario o para el académico, que también es un funcionario, es consustancial. No podemos privarnos, no podemos negarnos a esa participación.

En memoria de Pedro Fuenzalida Rodríguez 01.11.1965-27.03.2021 t. 